\title{
Production of Antifungal Compounds in Cowpea (Vigna sinensis) and Pea (Pisum sativum) after Virus Infection
}

\author{
By J. A. BAILEY \\ A.R.C. Plant Growth Substance and Systemic Fungicide Unit, \\ Wye College (University of London), Wye, Ashford, Kent
}

(Received I 8 October 1972)

\begin{abstract}
SUMMAR Y
Tissues of cowpea and pea underwent cellular browning following infection by tobacco necrosis virus and pea early browning virus respectively. In both species antifungal isoflavanoids accumulated in the brown tissues. The phytoalexins, phaseollidine, kievitone and phaseollin were isolated from virus-infected cowpea; pisatin from virus-infected pea. These results agree with previous indications that the destruction of host cells promotes the formation and accumulation of antifungal compounds within the tissues.
\end{abstract}

\section{INTRODUCTION}

Previous work has shown that when leaves or hypocotyls of bean (Phaseolus vulgaris) produce necrotic lesions in response to infection by tobacco necrosis virus (TNV), antifungal compounds (phytoalexins) accumulate in the tissues. Initially phaseollin was demonstrated (Bailey \& Ingham, I97I) but more recently the high concentrations of other antifungal compounds in TNV-infected hypocotyls has facilitated the isolation and identification of phaseollidin, phaseollinisoflavan and kievitone (Burden, Bailey \& Dawson, 1972). The present investigation was carried out to determine whether other plants, which undergo necrosis in response to virus infection, also accumulate antifungal compounds. The two species chosen, Vigna sinensis (cowpea) and Pisum sativum (pea), underwent cellular browning after inoculation with TNV and pea early browning virus (PEBV) respectively. Pea is known to produce the phytoalexin pisatin (Cruickshank \& Perrin, I96I), but phytoalexins have not been previously identified from cowpea. Smith (197I), however, reported that antifungal activity was found in diffusates from fungus-treated cowpea pods.

\section{METHODS}

Seeds of the cultivars of cowpea, cv. IVu 76 'Prima', and of pea, cv. Diktrom, were supplied by the International Institute of Tropical Agriculture, Ibadan, Nigeria, and the Pea Growing Research Organization respectively. The strain of TNV and its culture on Phaseolus vulgaris have been described (Bailey \& Ingham, I97I). PEBV, strain SP5, was kindly provided by Dr J. I. Cooper, Scottish Horticultural Research Institute, and maintained on Nicotiana clevelandii (Cooper \& Mayo, 1972). Etiolated hypocotyls of cowpea were grown as described for bean (Bailey \& Ingham, I 97I). Peas were grown at $22 \pm 2{ }^{\circ} \mathrm{C}$ under fluorescent lighting ( $4 \mathrm{~h}$ per day) until five leaves were fully expanded.

Hypocotyls or leaves were inoculated by rubbing with a small sponge soaked in either expressed sap (PEBV) or partially purified virus suspension (TNV) mixed with a little 600grade silicon carbide. The tissues were washed with distilled water and the plants incubated, 


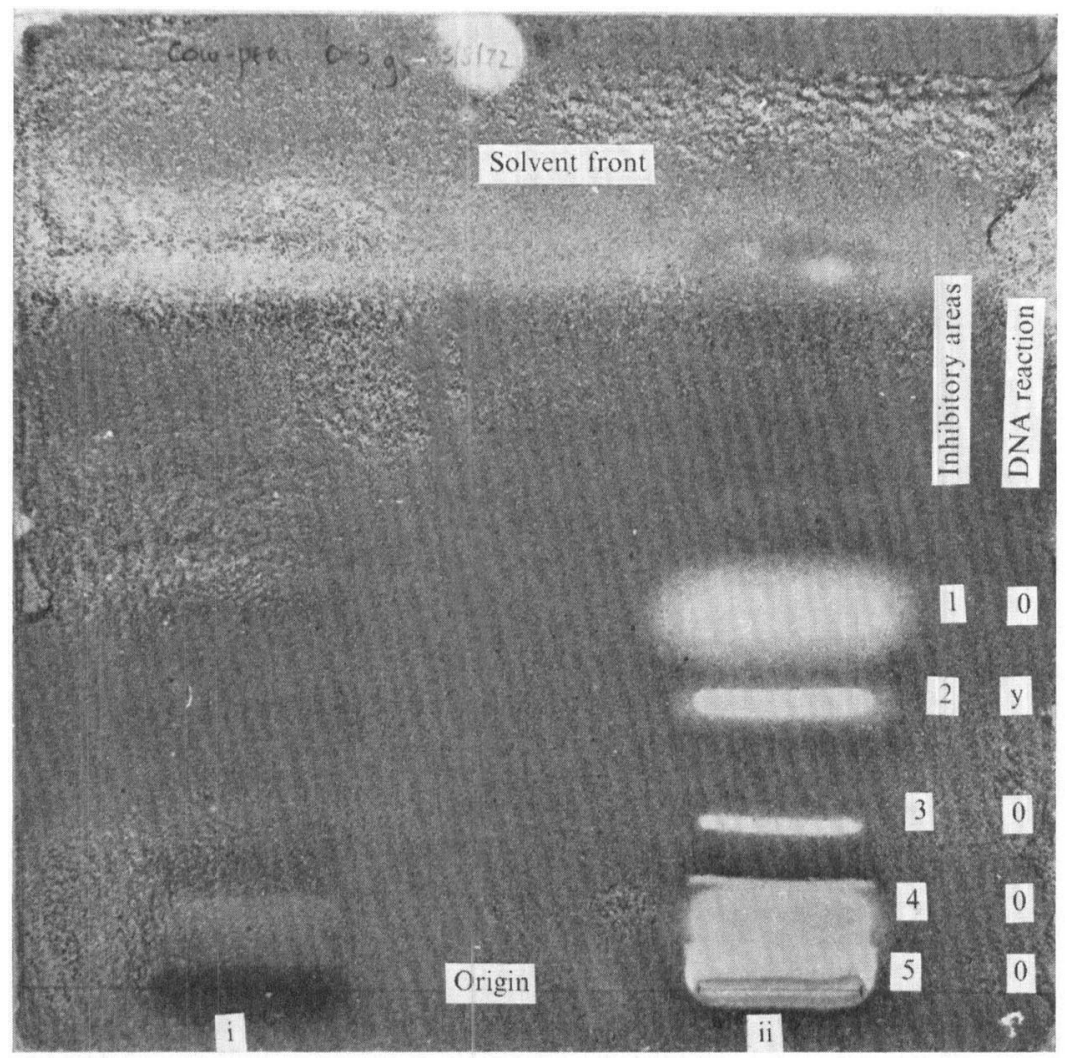

Fig. I. Occurrence of antifungal compounds in ether extracts of browned cowpea hypocotyls infected with TNV. Extracts of $0.5 \mathrm{~g}$ tissue were subjected to chromatography on silica in ethanol and chloroform $(3: 100)$. After drying, the plates were sprayed with a spore suspension of Cladosporium cucumerinum and incubated at $25{ }^{\circ} \mathrm{C}$ for 4 days. (i) Uninoculated tissue showing no visible browning. (ii) Tissue inoculated with TNV and showing extensive cellular browning. Nos. I to 5 refer to inhibitory areas. The letters $\mathrm{O}$ and $\mathrm{Y}$ indicate the colours, orange and yellow, which resulted when similar chromatograms were sprayed with diazotized $p$-nitroaniline.

as above, until symptoms were visible. The extraction of tissue, chromatography of extracts, bioassays and the isolation of phaseollidin, kievitone, phaseollin and pisatin have previously been reported (Cruickshank \& Perrin, I96I ; Bailey \& Deverall, I97 r; Bailey \& Burden, I973).

\section{RESULTS}

Symptoms of virus infections. Cowpea responded very rapidly to infection with TNV by producing orange-brown streaks, which were first visible $24 \mathrm{~h}$ after inoculation. Two days later this coloration extended throughout the hypocotyl. Discrete small brown lesions first appeared on leaves of pea 4 days after inoculation with PEBV, and these slowly increased in size for a further 6 days. However, they were neither extensive (usually 4 to $6 \mathrm{~mm}$ in diameter) nor abundant, and there was usually only one per leaf. When symptoms on both cowpea and pea had developed, the tissues were harvested, weighed and stored at $-20{ }^{\circ} \mathrm{C}$ for 2 to 3 days before extraction and bioassay.

Antifungal activity in ether extracts of TNV-infected cowpea. Ten $\mathrm{g}$ of uninoculated etiolated hypocotyls and of hypocotyls bearing necrotic lesions were extracted. Samples of each 


\section{Table 1. Concentration of phaseollidin, kievitone and phaseollin in ether extracts of TNV-infected cowpea hypocotyls}

Tissue $(4 \circ \mathrm{g})$ was extracted. Phaseollidin, kievitone and phaseollin were purified by thin-layer chromatography and the weight of each compound was measured by spectrophotometry.

\begin{tabular}{lccc} 
& \multicolumn{2}{c}{ Concentration } \\
\cline { 2 - 4 } & o.D. $\lambda_{\text {tnax }}$ & Total wt $(\mu \mathrm{g})$ & $\mu \mathrm{g} / \mathrm{g}$ fresh wt \\
Phaseollidin & $\mathrm{I} \cdot 20$ in $\mathrm{IO} \mathrm{ml}$ & $6 \mathrm{I} 2$ & $\mathrm{I} \cdot 3$ \\
Kievitone & $\mathrm{I} \cdot 52$ in $30 \mathrm{ml}$ & 1003 & $25 \cdot \mathrm{I}$ \\
Phaseollin & 0.17 in $10 \mathrm{ml}$ & 49 & $1 \cdot 3$
\end{tabular}

extract, equivalent to $0.5, \mathrm{I} \cdot 0$ and $2 \cdot 0 \mathrm{~g}$ of tissue, were applied to $3 \mathrm{~cm}$ origins on thin-layer plates and subjected to chromatography in ethanol and chloroform (3:100). When the plates had been developed and dried, the fungitoxic activity of the chromatographed extract was assayed directly by spraying with spores of Cladosporium cucumerinum suspended in Czapek Dox solution and incubating the plate in a moist chamber. The result obtained with the equivalent of $0.5 \mathrm{~g}$ tissue is shown in Fig. I. Five major areas of inhibition were revealed in extracts of virus-infected tissue, whereas none was observed in extracts of uninoculated tissue. For the purpose of reference only, these areas have been numbered I to 5 (Fig. I). Similar results were obtained with $2 \mathrm{~g}$ samples, except that a further band of inhibition was visible in the extract of virus-infected tissue slightly above area 3. When similarly developed plates were sprayed with diazotized $p$-nitroaniline reagent (van Sumere, Wolf, Teuchy \& Kint, 1965) the five areas of inhibition became orange-coloured except for area 2 which became yellow.

The inhibitory areas were further examined and the nature of the inhibitory components was investigated. The components of areas I and 4 (Fig. I) were isolated by thin-layer chromatography (Bailey \& Burden, 1973). Their $R_{F}$ values in several solvents and their u.v. spectra in neutral and alkaline ethanol were determined. All these measurements corresponded closely to those of authentic samples of phaseollidin and kievitone obtained from Phaseolus vulgaris (Burden et al. 1972). Furthermore, samples of kievitone obtained from both cowpea and bean, when methylated with diazomethane, gave products with identical chromatographic and spectroscopic properties.

The possible occurrence of phaseollin and phaseollinisoflavan, two other antifungal compounds which had also been isolated from bean (Burden et al. 1972), was then investigated. Phaseollinisoflavan was not found to be present in extracts of TNV-infected cowpea, whereas small amounts of phaseollin were detected. These amounts, however, were too small to be detected in the direct bioassays illustrated in Fig. I. The concentrations of phaseollidin, kievitone and phaseollin in the TNV-infected tissues were measured by spectrophotometry after thin-layer chromatographic separation. The results are shown in Table I.

Antifungal activity in ether extracts of PEBV-infected pea. Samples from an extract of Io $g$ of uninoculated and PEBV-inoculated pea leaves were assayed on thin-layer plates by using Cladosporium cucumerinum. The results, obtained with an extract equivalent to $0.5 \mathrm{~g}$ of tissue, are shown in Fig. 2. Again, extracts of virus-infected leaves contained an inhibitory component whilst extracts of uninoculated tissue did not. Similar results were obtained using $2 \mathrm{~g}$ samples.

The antifungal area was subjected to further purification by thin-layer chromatography, first in chloroform and then in hexane and acetone (4:I). The properties of the sample were 


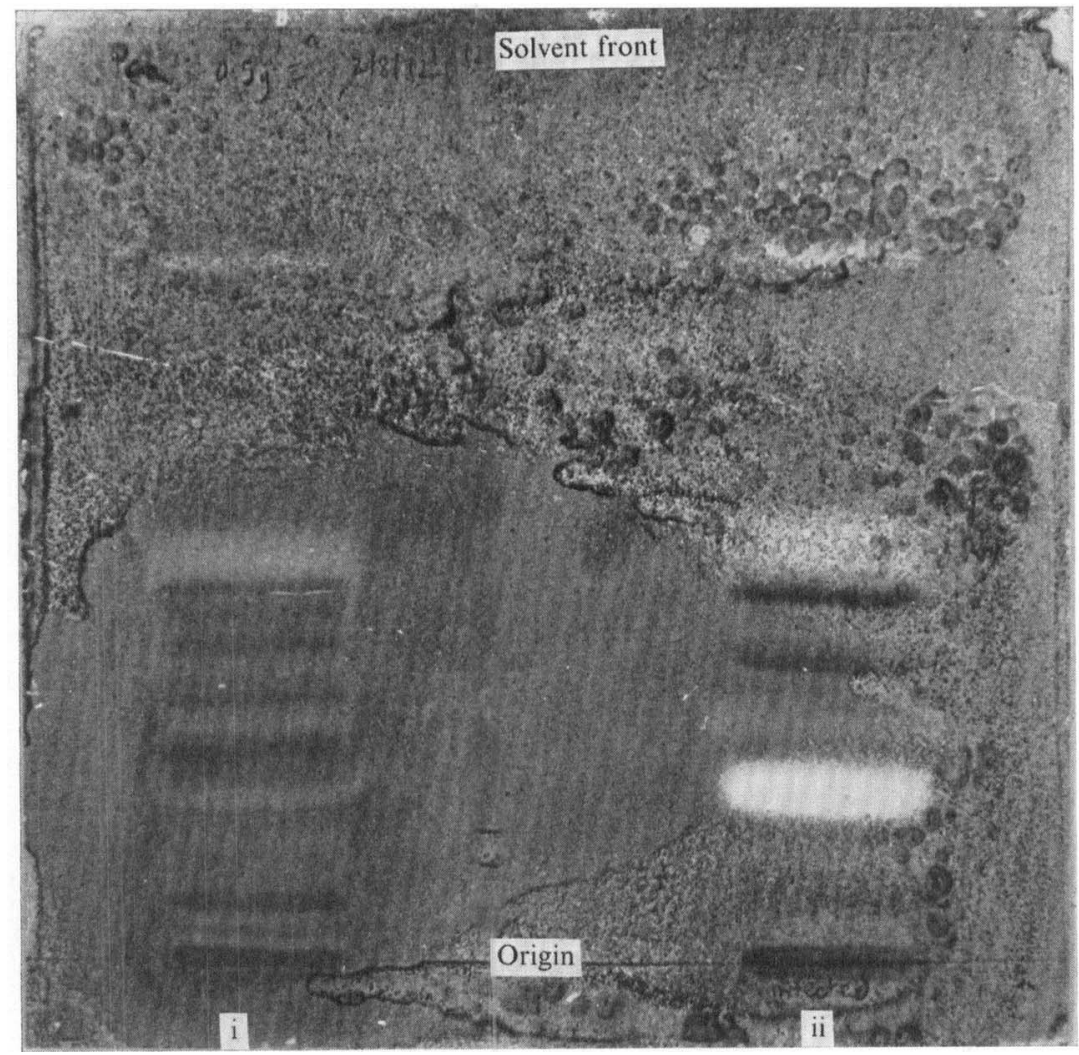

Fig. 2. Occurrence of antifungal compounds in ether extracts of pea leaves bearing necrotic lesions due to infection by PEBV. (i) Uninoculated leaves. (ii) Leaves inoculated with PEBV and bearing small necrotic lesions.

identical to those of another sample obtained from pods treated with $\mathrm{IO}^{-3} \mathrm{M}$-cupric chloride solution for $24 \mathrm{~h}$, and were similar in the following respects to those of pisatin: u.v. absorption spectrum in neutral ethanol; formation of anhydropisatin after the addition of hydrochloric acid; no change after the addition of sodium hydroxide; and ready partition into light petroleum (b.p. 40 to $60^{\circ} \mathrm{C}$ ) from aqueous solution (Cruickshank \& Perrin, I96I). Thus the presence of pisatin in the necrotic tissue was indicated.

The concentration of pisatin in different batches of PEBV-infected leaves, calculated by spectrophotometry after purification by thin-layer chromatography, varied from $\mathrm{I} \cdot 5 \mu \mathrm{g} / \mathrm{g}$ leaf (as in Fig. 2) to $\mathrm{I} 30 \mu \mathrm{g} / \mathrm{g}$ leaf.

\section{DISCUSSION}

The present experiments have demonstrated that both cowpea and pea produce antifungal compounds (phytoalexins) in the tissues which undergo cellular browning after infection by a virus. Cowpea produced several such compounds amongst which phaseollidin, kievitone and phaseollin have been identified. In contrast, pea produced one detectable inhibitory compound, pisatin. All these compounds have been isolated previously; those from cowpea from both fungus and virus-infected bean (Bailey \& Burden, 1973) and pisatin from fungus-infected pea (Cruickshank \& Perrin, 196r). Thus, the results support the 
suggestion (Bailey, 1973) that in legumes the postinfectional production of antifungal compounds is due to metabolism which results from processes associated with cell death.

Similar findings have recently been reported for soybean (Klarman \& Hammerschlag, 1972).

The significance of phaseollidin, kievitone and phaseollin in fungus-infected cowpea and the importance of these naturally occurring compounds in relation to fungal disease resistance are now being studied.

The author thanks Dr R. S. Burden for his valuable advice, Mr G. G. Vincent for his skilled technical assistance, Dr J. I. Cooper for advice on the culture of PEBV, Mr D. Simons for preparing the photographs and Professor R. L. Wain and Dr B. J. Deverall for helpful discussions.

\section{REFERENCES}

BAILEY, J. A. (1973). Phaseollin accumulation in Phaseolus vulgaris following infection by fungi, bacteria and a virus. In Fungal Pathogenicity and the Plant's Response. Edited by R. J. W. Byrde and C. V. Cutting. London: Academic Press.

Bailey, J. A. \& Burden, R. S. (1973). Biochemical changes and phytoalexin accumulation in Phaseolus vulgaris following cellular browning caused by tobacco necrosis virus. Physiological Plant Pathology (in the press).

Bailey, J. A. \& Deverall, B. J. (197I). Formation and activity of phaseollin in the interaction between bean hypocotyls (Phaseolus vulgaris) and physiological races of Colletotrichum lindemuthianum. Physiological Plant Pathology I, 435-449.

Bailey, J. A. \& INGhaM, J. L. (I97I). Phaseollin accumulation in bean (Phaseolus vulgaris) in response to infection by tobacco necrosis virus and the rust Uromyces appendiculatus. Physiological Plant Pathology I, $45 \mathrm{I}-456$.

Burden, R. S., Bailey, J. A. \& Dawson, G. W. (1972). Structures of three new isoflavanoids from Phaseolus vulgaris infected with tobacco necrosis virus. Tetrahedron Letters 4I, 4I 75-4178.

COOPER, J. I. \& MAYO, M. A. (1972). Some properties of the particles of three tobravirus isolates. Journal of General Virology I6, 285-297.

Cruickshank, I. A. M. \& Perrin, D. (196I). Studies on phytoalexins. III. The isolation, assay and general properties of a phytoalexin from Pisum sativum L. Australian Journal of Biological Science 14, 336-348.

Klarman, W. L. \& Hammerschlag, F. (1972). Production of the phytoalexin, hydroxyphaseollin, in soybean leaves inoculated with TNV. Phytopathology 62, 719-72I.

SмIтH, I. M. (197I). The induction of antifungal inhibitors in pods of tropical legumes. Physiological Plant Pathology 1, 85-94.

van Sumere, C. F., Wolf, G., Teuchy, H. \& Kint, J. (1965). A new thin-layer method for phenolic substances and coumarins. Journal of Chromatography 20, 48-60. 